\title{
Integrating ecological infrastructure in regional planning: a methodological case study from the Calgary region of western Canada
}

\author{
M. S. Quinn \& M. E. Tyler \\ Faculty of Environmental Design, University of Calgary, Canada
}

\begin{abstract}
The Calgary region of south western Alberta, Canada, like other areas of western North America, is experiencing dramatic population growth. The cumulative effects of rapid urbanization and land use intensification, specifically related to water use in a semi-arid region, are poorly understood. But, this needs to be considered in sustainable land use planning and policy development at a regional scale. There is a growing awareness among the municipalities in the Calgary area that a coordinated inter-municipal 'partnership' approach is needed to address long term regional growth management. We present an innovative methodology to incorporate landscape ecology and ecological infrastructure into strategic policy planning for regional development. Our approach involves the identification of critical ecological infrastructure related to landscape hydrology, the development of ecological performance criteria and preferred spatial development patterns related to landscape heterogeneity and connectivity and ecological infrastructure capacity. The methodology incorporates current urban ecology and landscape ecology thinking and encompasses both the 'gray' and 'green' infrastructure needs necessary to support regional population growth patterns. Three methodological tools are used to spatially 'link' ecological infrastructure performance, landscape heterogeneity and land use change over time. The methodology will be coupled with cellular automata scenario modelling at a watershed scale. The paper demonstrates key principles by focusing on two critical ecological facets of the Calgary area's regional landscape: landscape connectivity and landscape hydrology.

Keywords: ecological infrastructure, regional planning, sustainability, landscape management, ecological performance criteria, growth management, ecological design.
\end{abstract}




\section{Project background and overview}

The Calgary Regional Partnership (CRP) is an association of nineteen municipalities and communities representing $14,864 \mathrm{~km}^{2}$ and approximately 1.1 million people in and around the City of Calgary in western Canada. The region is characterized by the highest economic and population growth rates in Canada. The many benefits of growth are accompanied by a wide range of environmental, social, and economic issues. Among these issues is the impact of land use intensification on productive lands, regional habitat, and ecosystem function. The cumulative effects related to population growth and land use intensification pressure are poorly understood and to date, have not been integrated into land use and infrastructure planning and policy.

The region occupies a semi-arid transition zone along an elevation gradient from the height of the Rocky Mountains through to the foothills, northern fescue grassland, aspen parkland and mixed-grass prairie. Water availability is a critical limiting factor for the ecology of the region. Furthermore, the limiting effect of moisture is likely to increase given the regional climate modelling projections for warmer and drier conditions over the next $20-30$ years relative to the past 200 years (Schindler and Donahue [1]). The sustainability of future regional growth will, in part, be dictated by the spatial distribution of population growth and land use. Effective strategic planning requires moving away from conventional, technical water management approaches towards more integrative landscape ecology-based approaches that can address the existing policy gap between land use and water management (Ferreira and Botequilha Leitao [2]).

In 2006, three researchers from the University of Calgary joined forces with the CRP to initiate a research program in support of a Regional Growth and Sustainability Framework. This framework is in the formative stages but the integrative landscape research component is emerging as a transdisciplinary process integrating academic researchers from different disciplines with nonacademic professionals to pursue common goals and create new knowledge (Tress et al. [3]). The development of new knowledge is necessary because conventional research in the natural sciences does not address the type of interdisciplinary policy and management questions that need to be answered. Sustainable land use planning represents a social construct involving core values, economic self sufficiency, cultural heritage, multiple stakeholders and publicprivate partnerships as well as scientific knowledge. Our aim is to bridge the science-policy interface and explicitly address the uncertainty that characterizes complex bio-social systems. We operate from the perspective that people are part of the ecosystem and understanding inter-relationships between ecological patterns and processes involves integrating social patterns and processes (Zipperer et al. [4]). In this paper, we focus on the methodological framework and critical ecological elements of the integrated landscape research.

\section{Ecological infrastructure}

The term ecological infrastructure is used as a deliberate analogy to the engineered public works infrastructure systems of roads and utilities. Municipal 
(local government) infrastructure servicing systems enable the spatial distribution of energy, water and wastewater, material goods, services, and communications within the human landscape. Similarly, ecological systems distribute a variety of biotic and abiotic processes including the flow of water, energy, nutrients, and biotic organisms through networks of spatial interconnections in regional landscapes. These ecological infrastructure systems are responsible for the production of ecological goods and services (e.g., clean air, clean water and biodiversity) and are increasingly being 'valued' in monetary terms for inclusion in sustainable land use decision-making (Costanza et al. [5]).

Land use has significant effects on ecological infrastructure. For example, the most significant deleterious effects on regional hydrological systems are caused by land use change (Bhaduri et al. [6]). The conversion of native vegetation to agricultural, industrial or residential cover increases impermeable surface area and changes the characteristics of the regional hydrological cycle. Changes in land use also result in significant water withdrawals to support agricultural, induction and residential needs. Furthermore, changes in surface and ground water pathways and flows have consequences for a range of other environmental features such as river channel morphology, riparian structure and function, vegetation patch dynamics and biodiversity in general. Many of the changes arising from land use decisions are cumulative in nature, the effects of which may not be observable for decades (Haeuber and Hobbs [7]). Hence, understanding land use change effects on regional hydrological flux is a keystone of ecological management (Rogers and Defee [8]).

In practice, water resource management has focused on the management of aquatic features (such as wetlands, riparian zones, rivers, streams, lakes, or groundwater recharge/discharge zones) in the local and regional landscape that have water supply (quantity and quality) importance. Terrestrial landscape factors (including vegetation, geomorphology, aspect, soils, microclimate, macro and micro topography) functionally and spatially induce and regulate landscape moisture gradients; which in turn drive patch dynamics and meta-population dynamics. Sustainable land use planning and management requires greater consideration to these more invisible elements of water-land interface.

\section{Spatial ecology}

Strategic policy planning for sustainable regional growth management requires spatial decision-making. Urban growth, land use change, municipal servicing and ecosystem processes are all spatial phenomena. Therefore, landscape or spatial ecology provide a research framework for identifying and understanding spatial relationships, structural dimensions and preferred landscape development patterns for managing the critical ecological infrastructure related to soil moisture and landscape hydrology.

The goal of studying the spatial ecology of landscape hydrology and landscape heterogeneity inter-relationships is to identify methodological tools that can link water-related ecosystem components and processes (terrestrial and aquatic) at the landscape level with land use change and intensification driven by regional development pressures. The two primary research objectives are: 
- $\quad$ to assess the impact of land use intensification on water resources and landscape connectivity;

- $\quad$ to establish ecological performance criteria for testing alternative land use configurations against water-related ecological infrastructure capacity.

Landscape hydrology and landscape connectivity function as integrators of other key ecological functions including nutrient cycling, flooding, gene flow, and meta-population dynamics and were determined to be critical ecological infrastructure components for the region.

Configurational landscape heterogeneity plays a critical role in spatial ecology across scales. Heterogeneity refers to the spatial variation or diversity of habitat types and gradients within a landscape (Lovett et al. [9]). Landscape heterogeneity can be analysed three ways: as spatial units or 'patches', as gradients, or as 'neighbourhoods' in which neighbouring cells affect one another to varying degrees depending upon the distance from a focal patch. Spatial heterogeneity represents "the cumulative outcome of the processes affecting spatial and temporal distribution of vital resources such as water" meaning that patch dynamics can be linked to both urban landscape processes and differential soil water availability (Tongway and Ludwig [10, p.189]; see also Wu and Loucks [11]). The 'patchy' vegetation structure characteristic of semi-arid and arid landscapes is a function of source-to-sink processes within a "triggertransfer-reserve-pulse framework" (Ludwig [12]); which spatially redistributes moisture and nutrients between landscape patches. Therefore, understanding connectivity between patches is critical. Similarly, spatial heterogeneity is also a primary factor in rates of landscape change, as not all elements (gradients or patches) are equally sensitive to change (Thomas [13]).

Land use change and intensification affect spatial heterogeneity by altering the pattern of landscape variation. For example, suburban and exurban development affects patch structure (size, shape), patch interconnectivity and configurational and compositional variation (Alberti [14]). Different land use patterns can and do generate different ecological processes. Therefore, spatial patterns can be designed to facilitate certain types and levels of ecological performance such as soil moisture retention, vegetation distribution, biodiversity and nutrient cycling.

Landscape ecology focuses on the links between spatial pattern and ecological process. Consequently, landscape metrics should be useful tools for identifying, understanding and quantifying spatial-functional relationships in support of spatial planning. Principal component analysis of landscape metrics by Hahs and McDonnell [15] identified two metrics (landscape shape index and dominant land-cover type) that explained $77.9 \%$ of the variability in landscape pattern in Melbourne Australia's urban-rural gradient. Similarly, Kim and Pauleit [16] found four metrics particularly useful for evaluating ecological conditions in city regions in South Korea: landscape heterogeneity, patch shape, patch distance and patch context. We will evaluate and apply these and other metrics of landscape connectivity and landscape heterogeneity related to landscape hydrology patterns and processes. Large scale digital terrain 
modelling (Lavado Contador et al. [17]) will be linked with the metrics to assist in identifying near surface soil moisture patterns. A second type of metric will be used for urban development patterns and processes associate with cross-scalar connections between urban-rural gradient and moisture and nutrient retention.

\section{Connectivity analysis}

Connectivity is a key feature of landscape structure (Wiens [18]). Habitat fragmentation, defined as the conversion of large, contiguous blocks of habitat to smaller isolated patches of habitat, is the primary reason for the loss of biodiversity. Fragmentation associated with urbanization is recognized as one of the most significant causes of local extinctions and biodiversity loss (McKinney [19]). Therefore, maintaining or enhancing spatial connectivity is a key strategy in combating the long term effects of population growth pressures and land use change.

Landscape connectivity is the degree to which the landscape facilitates or impedes movement [dispersal] among resource patches (Taylor et al. [20]). The ecological process of dispersal is a critical function in the long-term maintenance of populations (Moilanen and Hanski [21]). The effective management and design of landscapes requires that quantitative measures of connectivity be derived and applied to the design of functional corridors (Anderson and Jenkins [22]). There are a variety of approaches to measuring connectivity that depend both on how connectivity is defined, what species are being considered and at what scale the questions are focused (Belisle [23], Marulli and Mallarach [24], Tischendorf and Fahrig [25]). Finally, connectivity is recognized as a threshold dynamic whereby gradual reduction may result in gradual effects until a critical threshold is exceeded and a dramatic effect is induced.

We are adapting the methodology for ecological connectivity analysis developed by Marulli and Mallarch [24] for the Barcelona Metropolitan Area. This approach is suitable to strategic assessments at the regional scale and can be implemented with the geo-spatial data gathered for other elements of the proposed research. The method entails a topological analysis of a land use map conducted within a geographic information system (ArcGIS). The first step in this approach is to identify ecological functional areas within the study area. In essence, this entails developing a classification for the habitat patches and matrices in the landscape. The classification will be driven by the ecological communities in the region, both native and human influenced. The second step is to identify barriers (landscape resistance) to movement of energy and matter within the overall landscape matrix. A barrier effect surface will be generated from a weighted list of barrier types, distance to barrier and the land use class affected by the barrier. Finally, a connectivity index will be generated through a cost-distance model that considers the ecological functional areas and the impedance surface. The resultant surfaces will be combined with an expertbased system to identify regional wildlife corridors. Validation of the approach will be conducted through finer scale analyses for selected indicator species. 


\section{Ecological performance metrics}

The ultimate purpose of identifying and quantifying critical components of ecological infrastructure is to establish policy, planning and management instruments for future sustainability. Analogous to building human infrastructure with specific capacities in mind (e.g., electrical grids and sewage lines of a sufficient size for the service area), quantitative targets and thresholds should be established for ecological performance. As with built infrastructure, the spatial distribution and spatial relationships with other landscape elements are a critical element of understanding performance (Alberti [14]). For example, simply stating the total linear distance of roads required to effectively provide a regional transportation network is not sufficient. One would need to develop criteria, as indeed transportation planners and engineers have, regarding the size of the various roads and their spatial pattern on the landscape. Likewise, the interaction between individual elements and the overall connectivity of ecological infrastructure is critical to its long-term sustainability. Hence, we caution against the use of single threshold values (e.g., $\mathrm{x} \%$ of native land cover must be maintained) and encourage the use of spatial landscape metrics

We are currently developing a landscape development intensity (LDI) index adapted from Brown and Vivas [26] and Alberti and Marzluff [27] but related to water use and landscape hydrology. Land use intensity is defined by Alberti [14, p.173] as "the ratio of population or jobs to area." Intensity is an important metric because it affects ecological landscape processes including landscape hydrology. An LDI index is a measure of the human disturbance gradient in the landscape. This gradient reflects the variation of human induced impacts on biological, chemical and physical landscape processes of terrestrial and aquatic ecological landscape features. It is based on land use and land cover and can be calculated for human disturbance gradients in watersheds of varying sizes. Development intensity factors in our adaptation of the method would be a function of water use per unit area of land use.

In order to manage ecosystem performance for the highest yield possible without irreversibly degrading system capacity, it is important to also identify the socio-economic forces driving land use change and intensification and the pressures that these forces are placing on water services (provision of water, regulation of water, and water movement in the landscape) in watershed context. The "Drivers-Pressure-State-Impact-Response" (DPSIR) assessment framework used by the United Nations Environment Program [28] and the European Environment Agency [29] will be adopted as a framework for identifying the critical driving forces that are affecting capacity and performance on a watershed basis. This method will incorporate two types of operators:

- "capacity indicators" related to landscape connectivity and land cover;

- "performance indicators" which are ecological service specific and related to land use intensification and spatial configuration affects on water provision, flow regulation and landscape hydrology. 


\section{Application to Cellular Automata modelling}

Over the last 10 years, Cellular Automata (CA) modelling has been used to simulate a wide range of dynamic spatial-temporal phenomena, including fire growth, rangeland degradation, and species propagation. The dominant field of application however is land use/cover change and urban development (White et al. [30]). These studies have demonstrated that $\mathrm{CA}$ is remarkably effective at generating realistic simulations of land use patterns and other spatial structures. They are dynamic and can explicitly represent spatial processes; they are rulebased, highly adaptable and can capture a wide range of processes; they are simple and computationally efficient, and despite their simplicity, they can exhibit extraordinarily rich behaviour ( $\mathrm{Li}$ and Yeh [31], White and Engelen [32]).

A central element in the integrated research program is the use of CA modelling to generate spatially explicit land use change scenarios for the CRP. A cellular automaton is a dynamic model in which space is represented as a matrix made of a regular arrangement of cells having the same dimension and shape. Each cell has a state value and evolves in time through simulation characterized by discrete time steps. Transition rules, applied at each time step, dictate how the different cell states will react to state configurations present in their neighbourhood. They are often applied uniformly and synchronously to all cells, but can also be applied non-uniformly to reflect the heterogeneity of the territory, and they may incorporate a distance-based weighting function. The neighbourhood can be local but extended neighbourhoods are also commonly used to take into account regions of influence of different sizes. These CA characteristics and the use of land cover classes in building the model are consistent with the spatial heterogeneity focus and landscape metrics being used to identify critical ecological infrastructure, connectivity and ecological performance as discussed in this paper. Although the landscape ecology work is being done in parallel with the development of the CA model; it will eventually be operationally linked with and contribute spatial constraints and transition rules for regional land use and growth management scenario generation. The information on regional ecological infrastructure will also constitute a critical component of the transdisciplinary multi-criteria evaluation process of alternative scenarios.

\section{Conclusion}

The Calgary region is representative of many rapidly growing and urbanizing regions. With very few exceptions, ecological infrastructure is not an integrated component of strategic policy and planning at the local government level. In large part this is due to a lack of methodologies currently available in general practice that can be used and customized at reasonable cost. Although only in the formative stages, the methodological approach outlined here will be put into practice and demonstrated with the CRP over the next two years. 


\section{Acknowledgements}

The authors would like to acknowledge our colleague, Dr. Danielle Marceau, Department of Geomatics Engineering, University of Calgary, for her contributions on cellular automata modelling. We are also grateful to the Calgary Regional Partnership for financial and collegial support of this initiative.

\section{References}

[1] Schindler, D.W., \& Donahue, W.F., An impending water crisis in Canada's western prairie provinces. Proceedings of the National Academy of Sciences, 103(19), pp. 7210-7216, 2006.

[2] Ferreira, H.S., \& Leitao, A.B., Integrating landscape and water-resources planning with focus on sustainability (Chapter 11), From landscape research to landscape planning: aspects of integration, education and applications, eds., B. Tress, G. Tress, G. Fry, \& P. Opdam, Springer: Dordrecht, pp. 143-159, 2006

[3] Tress, B., Tress, G., \& Fry, G., Defining concepts and the process of knowledge production in integrative research (Chapter 2). From landscape research to landscape planning: aspects of integration, education and applications, eds. B. Tress, G. Tress, G. Fry, and P. Opdam, Springer: Dordrecht, pp. 13-26, 2005.

[4] Zipperer, W.C., Wu, J., Pouyat, R.V. \& Pickett, S.T.A., The application of ecological principles to urban and urbanizing environments. Ecological Applications 10(3), pp. 685-688, 2000.

[5] Costanza, R., d'Arge, R., de Groot, R., Farber, S., Grasso, M., Hannon, B., Limburg, K., Naeem, S., O’Neill, R., Paruelo, J., Raskin, R.G., Sutton, P. \& van den Belt, M., The value of the world's ecosystem services and natural capital. Nature 387, pp. 253-260, 1997.

[6] Bhaduri, B., Harbor, J., Engel, B. \& Grove, M., Assessing watershedscale, long-term hydrologic impacts of land use change using a GIS-NPS model. Environmental Management 26(6), pp. 643-658, 2000.

[7] Haeuber, R.A. \& Hobbs, N.T., Many small decisions: incorporating ecological knowledge in land use decisions in the United States. Applying ecological principles to land management, eds. V.H. Dale \& R.A. Haeuber. Springer: New York, pp. 255-275, 2001.

[8] Rogers, G.O. \& DeFee, B.B., II., Long-term impact of development on a watershed: early indicators of future problems. Landscape and Urban Planning 73, pp. 215-233, 2005.

[9] Lovett, G.M., Jones, C., Turner, G. \& Weathers, K., Ecosystem function in heterogeneous landscapes (Chapter 1), Ecosystem function in heterogeneous landscapes, eds. G. Turner \& K. Weathers, Springer: New York, pp. 1-4, 2005.

[10] Tongway, D.J. \& Ludwig, J.A., Heterogeneity in arid and semi-arid lands (Chapter 10), Ecosystem function in heterogeneous landscapes, eds. G. Turner \& K. Weathers, Springer: New York, pp. 189-206, 2005. 
[11] Wu. J. \& Loucks, O.L., From balance of nature to hierarchical patch dynamics: a paradigm shift in ecology. Quarterly Review of Biology 70, pp. 439- 466, 1995.

[12] Ludwig, J.A., Disturbances and landscapes: the little things count (Chapter 6), Issues and perspectives in landscape ecology, eds. J. Wiens \& M. Moss, Cambridge University Press: Cambridge, pp. 42-51, 2005.

[13] Thomas, M., Landscape sensitivity and timescales of landscape change (Chapter 14), Issues and perspectives in landscape ecology, eds. J. Wiens \& M. Moss, Cambridge University Press: Cambridge, pp. 131-151, 2005.

[14] Alberti, M., The effects of urban patterns on ecosystem function. International Regional Science Review 28(2), pp. 168-192, 2005.

[15] Hahs, A.K. \& McDonnell, M.J., Selecting independent measures to quantify Melbourne's urban-rural gradient. Landscape and Urban Planning 78, pp. 435-448, 2006.

[16] Kim, K.H. \& Pauleit, S., Landscape metrics to assess the ecological conditions of city regions: application to Kwangju City, South Korea International Journal of Sustainable Development \& World Ecology 12: 227-244, 2005.

[17] Lavado Contador, J.F., Maneta, M. \& Schnabel, S., Prediction of nearsurface moisture at large scale by digital terrain modeling and neural networks. Environmental Monitoring and Assessment 121 (1-3), pp. 211 230, 2006.

[18] Wiens, J.A., Toward a unified ecology (Chapter 35). Issues and perspectives in landscape ecology, eds. J. Wiens \& M. Moss, Cambridge University Press: Cambridge, pp. 365-373, 2005.

[19] McKinney, M., Urbanization, biodiversity and conservation. Bioscience 52(10), pp. 883-890, 2002.

[20] Taylor, P.D., Fahrig, L., Henein, K. \& Merriam, G., Connectivity is a vital element of landscape structure. Oikos 68, pp. 571-573, 1993.

[21] Moilanen, A. \& Hanski, I., On the use of connectivity measures in spatial ecology. Oikos 95(1), pp. 147-151, 2001.

[22] Anderson, A.B. \& Jenkins, C.N., Applying nature's design: corridors as a strategy for biodiversity. Columbia University Press: New York, 2006.

[23] Belisle, M., Measuring landscape connectivity: the challenge of behavioral landscape ecology. Ecology 86(8), pp. 1988-1995, 2005.

[24] Marulli, J., \& Mallarach, J.M., A GIS methodology for assessing ecological connectivity: application to the Barcelona Metropolitan Area. Landscape and Urban Planning, 71, pp. 243-262, 2005.

[25] Tischendorf, L. \& Fahrig, L., How should we measure landscape connectivity? Landscape Ecology 15, pp. 633-641, 2000.

[26] Brown, M.T. \& M.B., Vivas Landscape development intensity index. Environmental Monitoring and Assessment 101, pp. 289-309, 205.

[27] Alberti, M. \& Marzluff, J.M., Ecological resilience in urban ecosystems: linking urban patterns to human and ecological function. Urban Ecosystems 7, pp. 241-265, 2004. 
[28] Denisov, N., Grenasberg, M., Hislop, L., Schipper, E.S. \& Sørensen, M., Cities environmental reports on the internet: understanding the CEROI template. UNEP/GRID: Arendal, Norway, 2000.

[29] European Environment Agency, Toolbox for European harmonised procedures for quantification of nutrient losses from diffuse sources. EUROHARP: Copenhagen, Denmark, 2001.

[30] White, R., Engelen, G. \& Uljee, I., Modelling land use change with linked cellular automata and socio-economic models. Spatial information for land use management, eds. M.J. Hill \& R.J. Aspinall, Gordon \& Breach: London, pp. 189-204, 2000.

[31] Li, X. \& Yeh, A.G. Modelling sustainable urban development by the integration of constrained cellular automata and GIS. International Journal of Geographical Information Science 14(2), pp. 131-152, 2000.

[32] White, R. \& Engelen, G. High-resolution integrated modelling of the spatial dynamics of urban and regional systems. Computers, Environment and Urban Systems 24(5), pp. 383-400, 2000. 